\title{
Prospects of Using High-Throughput Proteomics to Underpin the Discovery of Animal Host-Nematode Interactions
}

\author{
Tao Wang *(D) and Robin B. Gasser
}

Department of Veterinary Biosciences, Melbourne Veterinary School, Faculty of Veterinary and Agricultural Sciences, The University of Melbourne, Parkville, VIC 3010, Australia; robinbg@unimelb.edu.au

* Correspondence: tao.wang1@unimelb.edu.au

\begin{abstract}
Parasitic nematodes impose a significant public health burden, and cause major economic losses to agriculture worldwide. Due to the widespread of anthelmintic resistance and lack of effective vaccines for most nematode species, there is an urgent need to discover novel therapeutic and vaccine targets, informed through an understanding of host-parasite interactions. Proteomics, underpinned by genomics, enables the global characterisation proteins expressed in a particular cell type, tissue and organism, and provides a key to insights at the host-parasite interface using advanced high-throughput mass spectrometry-based proteomic technologies. Here, we (i) review current mass-spectrometry-based proteomic methods, with an emphasis on a high-throughput 'bottom-up' approach; (ii) summarise recent progress in the proteomics of parasitic nematodes of animals, with a focus on molecules inferred to be involved in host-parasite interactions; and (iii) discuss future research directions that could enhance our knowledge and understanding of the molecular interplay between nematodes and host animals, in order to work toward new, improved methods for the treatment, diagnosis and control of nematodiases.
\end{abstract}

Keywords: parasitic nematode; host-parasite interactions; mass spectrometry (MS); high-throughput proteomics; LC-MS/MS

\section{Introduction}

Diseases caused by parasitic nematodes do not only impose a significant public health burden, but also cause major economic losses to agriculture in the subtropical and tropical countries [1]. Globally, soil-transmitted nematodes alone (e.g., Ascaris lumbricoides, Ancylostoma duodenale, Necator americanus and Trichuris trichiura) infect $~ 472$ million people, leading to a burden of $\sim 4$ million disability-adjusted life-years (DALYs) [2]. In the livestock industry, productivity and financial losses of tens of billions of dollars per annum have been estimated as a consequence of parasitic nematode infections and diseases (nematodiases) [3]. The control of nematode infections currently relies largely on the use of a limited number of anthelmintic drugs, but there is now widespread resistance in nematodes of livestock animals to most of classes of these anthelmintics. This situation means that there is an urgent need for improved interventions, including novel drug treatments and vaccines $[4,5]$. While vaccines could provide a safe and sustainable solution, progress in developing highly protective anti-nematode vaccines has been limited. Barbervax ${ }^{\circledR}$ and Bovilis ${ }^{\circledR}$ Huskvac are two of the few examples of effective vaccines against haemonchosis and lungworm disease, respectively, which have been licensed and commercialised [6]. To some extent, limited advances in this area relate to a lack of understanding of the intricate relationships between host animals and their nematode parasites as well as host immune responses induced and evasion mechanisms employed by these parasites. Clearly, the search for new intervention targets will require detailed studies of host-parasite interactions at the molecular level $[7,8]$.

In the past two decades, with substantial progress made in the development and adoption of nucleic acid sequencing technologies (e.g., next-generation sequencing) and 
associated bioinformatics (e.g., automated assembly and annotation tools/pipelines), a range of genomes and transcriptomes of parasitic nematodes have been decoded, which has significantly facilitated biological explorations of these worms at the biochemical and molecular levels $[9,10]$. As the building blocks of cells, proteins directly perform critical biofunctions of genes via enzymatic catalysis, cell signalling, signal transduction as well as protein-molecule (i.e., DNA, lipid, carbohydrate and other protein) interactions. In this postgenomic era, a key research agenda is to reveal the expression patterns and functions of nematode genes in different developmental stages and sexes, and to gain a sound understanding of critical pathways and biological processes that molecules in nematodes are involved in [11-14].

Mass spectrometry (MS)-based proteomics represents an integral postgenomic technology that can be used to characterise all proteins expressed in a particular cell type, tissue and/or organism under a defined set of conditions. The use of such technology allows biological insights via protein identification, quantification, localisation and the definition of post-translational modifications, as well as the elucidation of protein dynamics and functions at the host-parasite interface linked to host invasion, parasite survival, host immune evasion and immunoregulation $[15,16]$. The availability of draft genomes and transcriptomes for $>100$ species of nematodes (Parasite WormBase; 28 May 2021) now strongly underpins the expansion of mass-spectrometry-based proteomic studies of parasitic nematodes.

In the present article, (i) we review MS-based proteomic approaches available to explore parasitic worms, with an emphasis on the high-throughput 'bottom-up' approach; (ii) we appraise recent advances that have been made in the study of the proteomes of parasitic nematodes of animals, highlighting proteins inferred to be involved in hostparasite interactions, and (iii) we provide a perspective on areas of future work that should assist in gaining an enhanced understanding of the molecular interplay of nematodes with their hosts.

\section{Mass-Spectrometry-Based Proteomics Approaches Applied to Study Parasitic Nematodes}

There are two types of MS-based proteomic strategies: 'top-down' and 'bottom-up'. The 'top-down' approach refers to the direct measurement of intact proteins, enabling the characterisation of proteins without the need of an annotated reference genome [17]. Although it provides advantages for the definition of post-translational modifications, the 'top-down' approach is considered to be less suited for the high-throughput characterisation of complex samples due to technological challenges associated with fractionation and ionisation of proteins and fragmentation in the gas phase $[17,18]$. On the other hand, the 'bottom-up' approach is based on the analysis of small peptides obtained following extensive proteolytic digestion, and allows the large-scale characterisation of complex mixtures of molecules derived from whole worms, organ systems, tissues or cells. This approach allows the analysis of thousands of proteins, including those of low abundance, in a single run within a short time-frame (1-2 h) (reviewed in [17]). Advances in MS technologies and the availability of annotated nuclear genomes have meant that the proteomic investigation of proteins in complex samples (i.e., whole nematodes or tissues thereof) has shifted from 'top-down' to 'bottom-up'.

Three main workflows are used for 'bottom-up' proteomics, applicable depending on sample complexity and the objectives of the analysis:

(i) 'Targeted' proteomics: Here, selected/multiple reaction monitoring (SRM/MRM) and parallel reaction monitoring (PRM) are two commonly used methods $[18,19]$. Using triple-quadrupole, quadrupole-ion trap or quadrupole-time-of-flight (TOF) instruments, SRM/MRM methods allow precursor ions with expected mass to pass through a first phase of MS (MS1), after which multiple fragmented ions from the selected precursor ions are screened in a second phase of MS analysis (MS2) for target detection. In MS1 and MS2, spectrum scans are separated by a defined mass-to-charge $(\mathrm{m} / \mathrm{z})$ 
value. SRM/MRM enables rapid profiling of pre-determined and known subsets of proteins of interest with high specificity and quantitative accuracy, regardless of different treatments or conditions of samples [18,19]. PRM is an ion monitoring technique performed using a quadrupole-Orbitrap mass spectrometer. The principle of this technique is comparable to SRM/MRM, but assay development is more convenient. Unlike SRM, which performs one transition at a time, PRM performs a full scan of each transition by a precursor ion (i.e., parallel monitoring of all fragments from a precursor ion). Thus, PRM can be applied to analyse complex samples to achieve absolute quantification of multiple proteins to an attomole-level [18]. Nevertheless, SRM/MRM and PRM methods are less suited for discovery-based proteomics.

(ii) Data-independent acquisition (DIA): This method allows the analysis of all peptides within a defined $m / z$-range to be fragmented and analysed in MS2. The aim of this method is to obtain comprehensive fragmentation mapping of proteins in highly complex samples without being limited to profiling pre-determined peptides of interest. However, there is a technical limitation in the coverage of precursor ions using the DIA approach. Consequently, it is common practice to generate 'pseudo' fragment ion mass spectra prior to database searching

(iii) Shotgun proteomics: This method [20] resembles the shotgun DNA-sequencing approach used in the genomics field. Here, proteins are digested enzymatically and subjected to liquid chromatography tandem MS (LC-MS/MS) in a data-dependent acquisition (DDA) mode. Peptides are identified by matching the mass spectra of peptide fragments with theoretical mass spectra calculated for proteins of an organism represented in an annotated genome available via a public database. Shotgun proteomics is now the 'mainstream' approach used for proteomic studies of parasitic nematodes. The latest applications of high-throughput proteomics to parasitic nematodes of animals are summarised in the following section. We have elected to include studies published in the last five years, because this is when most progress has been made using high-throughput proteomics due the availability of informative nuclear genomic data sets for selected socioeconomically important parasitic nematodes of animals.

\section{Recent High-Throughput Proteomic Explorations of Parasitic Nematodes}

Critical for the establishment and survival of a parasitic nematode (parasitism) in its host are the processes of host invasion, migration, feeding, reproduction and the establishment of a 'balanced' interaction with the host animal [21]. Such 'cross-talk' begins when the worm invades the host and is then maintained, relatively consistently, during the phase of parasitism. It is believed that not only does the nematode suppress host immune responses via the release of parasite-derived immunomodulators (such as secretory proteins, products and vesicles), but the host can also regulate the synthesis of proteins and other molecules in the worm [21-24].

\subsection{The Secretome}

Excretory-secretory (ES) proteins, including those actively released from the worm gut or the cuticular surface of nematode, can play key roles at the parasite-host interface. An in silico-prediction study [25] showed that the full complement of ES proteins (called 'secretome') represents a considerable proportion ( $8 \%)$ of the nematode proteome. Many ES proteins represent essential molecules, such as hormones, proteases and antimicrobial peptides, which indicates that this molecular subset could present suitable targets for drugs or vaccines [26,27]. Hence, recent high-throughput proteomic studies mainly focused on comprehensive analyses of ES proteins (Table 1). Typically, ES proteins of parasitic nematodes are collected from in vitro-cultured parasites and then concentrated prior to LC-MS/MS analysis. Intriguingly, many of the ES proteins (described in the following) identified/characterised are not only abundant in numerous nematode species from distinct taxonomic groups, but also seem to be regulated in a stage-specific manner. They 
are suggested to be involved in facilitating host invasion, migration as well as nutrient acquisition, antibacterial or antioxidant activities and/or immune evasion or suppression, enabling nematode survival.

Hookworms and related worms. Hookworms (i.e., Necator americanus, Ancylostoma duodenale and Ancylostoma ceylanicum; family Ancylostomatidae) infect about half a billion people worldwide and are a significant threat to human health, particularly in underprivileged communities [28]. The secretomes of hookworm species are relatively well characterised compared with other parasitic nematodes. Initial studies of selected hookworm ES proteins began in the 1990s [29] and, subsequently, an emphasis was placed on the global characterisation of hookworm secretomes [30]. This led to the identification a series of potential anti-hookworm vaccine targets, such as sperm-coating proteins/Tpx1/Ag5/PR-1/Sc7 (SCP/TAPS) and calreticulin [30].

Advances in high-throughput proteomic techniques and the accessibility of hookworm genomes have allowed significant progress in studying hookworm-host interactions. A particular example is the recent study of the dog hookworm Ancylostoma caninum. Using advanced LC-MS/MS combined with in-gel and off-gel electrophoresis, in 2017, Morante et al. [31] identified nearly three times $(n=315)$ the number of proteins reported previously $(n=105)$ by Muvenna et al. [32] in 2009. Facilitated by state-of-the-art MS and underpinned by genomic information, a re-analysis of the proteome only required a quarter of previously required amount of ES products (equating to $150 \mu \mathrm{g}$ of protein versus $660 \mu \mathrm{g}$ previously) [32]. Importantly, a number of 'novel' proteins (e.g., cysteine proteases ANCCAN_06649, ANCCAN_06644, ANCCAN_30567, ANCCAN_6619 and ANCCAN 06647) with immunogenic potential were reported for the first time.

Most previous studies of hookworm secretomes were conducted using Nippostrongylus brasiliensis, Ancylostoma caninum and Ancylostoma celyanicum, which can readily be maintained in animal models [33], facilitating the production of parasite materials for analyses. However, it was not until 2020 that the first comprehensive proteomic analysis of a secretome of a human hookworm was reported [34]. In this study of Necator americanus [34], a total of 198 ES proteins were identified in the adult stage, $90 \%$ of which had homologs in the secretomes of three other strongylid nematodes (i.e., Ancylostoma caninum, Heligmosomoides polygyrus/bakeri and Nippostrongyus brasiliensis) [31,35,36], confirming the value of these reference species for such studies. Of the $198 \mathrm{ES}$ proteins identified/characterised for adult Necator americanus, $~ 30 \%$ of them belong to the group of SCP/TAPS proteins with one or two 'SCP' domains [34]. SCP/TAPS proteins are cysteine-rich secretory proteins, and are commonly detected in the secretomes of parasitic nematodes, particularly hookworms [37]. These proteins are believed to play key roles during host invasion, the penetration of tissues (e.g., skin, mucosa and connective tissues) and the transition from the free-living to parasitic stages for many nematode species [38], although the exact functions of many members of this family remain to be established. SCP/TAPS proteins have been shown to be abundant in the proteomes of a number of nematode species within clades IV and V, such as Ancylostoma caninum, Teladorsagia circumcincta and Strongyloides ratti [34,38]. Notably, a recent study of the secretome of Heligmosomoides polygyrus/bakeri (family Trichostrongylida) showed that interactions between the sexes of this species influence the composition and abundance SCP/TAPS proteins. Specifically, SCP/TAPS proteins collected from mixedsex cultures of fourth-stage larvae (L4s) of Heligmosomoides polygyrus/bakeri were more abundant than those harvested from either females or males [39].

Haemonchus contortus. Taking advantage of recently-updated genomic resources [40], Wang and co-workers [41] characterised ES proteins representing four distinct developmental stages or sexes (i.e., L3, L4, adult male and adult female) of Haemonchus contortus-the barber's pole worm of ruminants. A total of 878 unique ES proteins were identified and quantified. ES proteins, such as proteases, SCP/TAPS proteins, glycoside hydrolases, Ctype lectins and transthyretin-like proteins, were not only found to be abundantly secreted in one or more developmental stages of Haemonchus contortus, but there were marked differences in abundance between or among stages, indicating that some of these molecules 
(particularly proteases and glycoside hydrolases) are involved in nutrient digestion and acquisition as well as parasite-host interactions during the transition from the free-living to the parasitic phase [41]. In particular, the abundance of glycoside hydrolases $(n=13)$ in the secretomes of parasitic stages (i.e., L4 and adults) [41] is of particular interest, because, based on an earlier study [42], such hydrolases are indispensable molecules for energy metabolism in gut-dwelling parasites, such as Ascaris suum, although they have not been previously identified as abundant in parasitic nematodes that ingest blood as their main diet. This discovery, revealed using an advanced high-throughput proteomic approach, appears to have shed light on an alternative energy supply pathway in Haemonchus contortus, which takes place via the degradation of complex sugars.

Considerable effort has also gone into identifying and evaluating immunogenic proteins present in the secretome of Haemonchus contortus [43-45]. Using co-immunoprecipitation, combined with shotgun LC-MS/MS, Lu et al. [45] identified 114 ES proteins that interact with host T cells, including a series of proteases, SCP/TAPS proteins and C-type lectins. Thus, this study provided a first insight into the interplay between this parasite (via ES products) and the immune system (via effector cells), and also proposed possible vaccine candidates, such as the $\alpha / \beta$-hydrolase domain protein (HcABHD), of which a recombinant version has been reported to achieve up to $70 \%$ protection against Haemonchus contortus challenge infection in a subsequent study [44].

Teladorsagia circumcincta. Proteomics has also been carried out on Teladorsagia circumcincta - the brown stomach worm of small ruminants-to characterise tissue-specific ES proteins. Using LC-MS/MS coupled with comparative two-dimensional gel electrophoresis, Price and colleagues [46] identified 17 differentially released proteins, 14 of which were enriched in the secretome of mucosal-dwelling L4s of Teladorsagia circumcincta, and three of which were identified in lumen-dwelling larvae. Of the latter three proteins, peroxiredoxin was proposed to play an antioxidant role in helping mucosal-dwelling worms scavenge and eliminate host-derived reactive oxygen species.

Angiostrongylus cantonensis. A proteomic analysis of ES products from young adults of Angiostrongylus cantonensis using LC-MS/MS [47] identified > 250 proteins, of which disulphide isomerase and calreticulin were abundantly represented. Western blot analysis inferred a disulphide isomerase, an aspartic protease, an annexin and five presently unknown proteins that induced an antibody response in infected mice [47].

Trichuris species. Trichuris muris (of mouse) and Trichuris suis (of swine) have been extensively used in animal models to study trichuriasis. Recent studies of proteins secreted from Trichuris muris employing LC-MS/MS have provided insight into aspects of host-whipworm interactions. For instance, Eichenberger et al. [48] identified 148 secreted proteins in adult Trichuris muris, including several protease inhibitors, such as secretory leukocyte proteinase inhibitor (SLPI)-like proteins, which play key roles in immunomodulation and wound healing [49]. In a study of Trichuris suis, Leroux et al. [50] identified 328 ES proteins, many homologs of which have been reported for other nematodes, including Trichuris muris, Ascaris suum and Haemonchus contortus, and are purported to be involved in inducing or modulating host immune responses.

Trichinella species. Immunoproteomic studies of Trichinella spiralis, Trichinella pseudospiralis and Trichinella britovi have focused on ES proteins [51-55], with the intention of improving the immuno- or sero-diagnosis of trichinellosis. Numerous immunogenic proteins, including serine protease, enolase and peptidase inhibitors, were recognised by antibodies in the sera from patients or from experimental animals. These findings might provide guidance on selecting antigens for early diagnosis and possible vaccine candidates.

There has been an increased attention on proteases secreted by Trichinella. It is believed that such proteins assist the parasite during the invasion and tissue migration phases, and modulate immune responses at the host-parasite interface in multiple ways [56,57]. Using zymography, combined with shotgun LC-MS/MS, 29 proteins inferred to be proteases were identified in the secretome of infective larvae (L1s) of Trichinella spiralis taken from the host intestine [58]. In this species, the transcription of selected genes encoding two 
serine proteases - a cathepsin B-like cysteine proteinase and a zinc metalloproteinase-in the larval stage was shown by qPCR to be markedly higher than in muscle larvae. Based on these findings, it was proposed that the proteolytic enzymes directly exposed to the host intestinal milieu may mediate the worm's penetration of the enteral epithelium and assist in immune evasion during parasite invasion and migration in the host animal.

Table 1. Summary of recent high-throughput proteomic studies of excretory-secretory proteins from species of parasitic nematodes.

\begin{tabular}{|c|c|c|c|c|}
\hline Nematode Species & Developmental Stages & Analytical Approach & $\begin{array}{l}\text { No. of Proteins } \\
\text { Identified }\end{array}$ & $\begin{array}{c}\text { Year; } \\
\text { Reference }\end{array}$ \\
\hline Ancylostoma caninum & Adult worms (both sexes) & Proteomics; LC-MS/MS & 315 & $2017 ;[31]$ \\
\hline Heligmosomoides polygyrus & L4s (mixed and separate sexes) & Proteomics; LC-MS/MS & 258 & $2021 ;[39]$ \\
\hline Necator americanus & Adult worms (both sexes) & Proteomics; LC-MS/MS & 198 & $2020 ;[34]$ \\
\hline \multirow[t]{2}{*}{ Haemonchus contortus } & L3s, L4s and adults (separate sexes) & Proteomics; LC-MS/MS & 878 & $2019 ;[41]$ \\
\hline & Adult worms (both sexes) & Immunoproteomics; LC-MS/MS & 114 & $2020 ;[45]$ \\
\hline Trichuris muris & Adult worms (both sexes) & Proteomics; LC-MS/MS & 148 & 2018; [48] \\
\hline Trichuris suis & L4s and adults (both sexes) & Proteomics; LC-MS/MS & 354 & 2018; [50] \\
\hline Teladorsagia circumcincta & L4s & Proteomics; LC-MS/MS & 17 & $2019 ;[46]$ \\
\hline \multirow[t]{3}{*}{ Trichinella spiralis } & Muscle larvae & Immunoproteomics; LC-MS/MS & 17 & $2020 ;[53]$ \\
\hline & Intestinal infective larvae & Immunoproteomics; LC-MS/MS & 30 & $2021 ;[58]$ \\
\hline & Adult worms (both sexes) & Proteomics; LC-MS/MS & 10 & $2016 ;[54]$ \\
\hline Trichinella britovi & 'Muscle' larvae & Immunoproteomics; LC-MS/MS & 18 & 2020; [53] \\
\hline \multirow[t]{2}{*}{ Trichinella pseudospiralis } & 'Newborn' larvae and adults & $\begin{array}{c}\text { Immunoproteomics; } \\
\text { MALDI-TOF/TOF-MS/MS }\end{array}$ & 28 & $2017 ;[52]$ \\
\hline & Muscle larvae (three isolates) & Proteomics; LC-MS/MS & 2591 & 2020; [51] \\
\hline Strongyloides venezuelensis & L3s and female adults & Proteomics; LC-MS/MS & 436 & 2019; [59] \\
\hline Angiostrongylus cantonensis & Adult worms (both sexes) & Proteomics; LC-MS/MS & 254 & 2019; [47] \\
\hline
\end{tabular}

Abbreviations: L3s, the third-stage larvae, L4s, the fourth-stage larvae; MALDI, matrix-assisted laser desorption/ionisation; LC, liquid chromatography; MS, mass spectrometry; TOF, time-of-flight.

Strongyloides venezuelensis. This intestinal nematode of rodents is commonly used as a laboratory model to study the biology of Strongyloides more generally. Using LC-MS/MS, Maeda et al. [59] characterised 196 and 436 proteins secreted from respective adult female and infective larvae (L3s) of Strongyloides venezuelensis. The proteins most abundantly secreted from adult worms were those associated with glycolysis and DNA binding, whereas abundant molecules released from the L3 stage were linked to peptidase activity, embryo development and the oxidation-reduction process. Of note, a comparative analysis of protein and gene expression levels linked to secreted proteins in samples collected before and after in vitro-culture showed that secreted proteins were already expressed and accumulated in 'pre-infection' L3s, so that the proteins required are ready to be released as soon as the worm infects the host animal. These findings provide some support for the key role of ES proteins during host invasion.

\subsection{Extracellular Vesicles (EVS)}

A growing number of studies has shown that, in addition to soluble molecules (e.g., proteins, lipids and glycans), ES products of parasitic nematodes contain other parasitederived extracellular vesicles (EVs). EVs, ranging in size from $40 \mathrm{~nm}$ to $150 \mathrm{~nm}$, are tiny membrane-bound vesicles shed by most cells, which relate to a previously-overlooked role in delivering molecules to other cells. Based on the size of such vesicles, at least two types of EVs from parasitic nematodes have been described, namely exosomes (or "120 k") and microvesicles (or "15 k") [24,60]. EVs released by parasitic nematodes contain particular nucleotides (e.g., microRNAs), proteins (e.g., enzymes and toxins) and/or signalling lipids, and are likely involved in modulating innate and/or adaptive immune responses [61].

The active release of EVs from parasitic nematodes has been witnessed for key nematode species, including Ascaris suum [62], Brugia malayi [63,64], Heligmosomoides polygyrus [65], Nippostrongylus brasiliensis [66], Teladorsagia circumcincta [67], Trichinella spiralis [68], Trichuris suis [69,70] and Trichuris muris [48,71,72]. Given the important roles proposed for EVs at the host-nematode interface, high-throughput proteomics has been 
exceptionally useful to characterise the protein composition of EVs from mainly adult stages of these parasites. It is important to consider, however, that this is an emerging field of study and, as yet, the number of proteins identified in different studies of EVs varies considerably [60]. For instance, a marked difference in the number of EVs proteins (73 versus 364) identified in the whipworm Trichuris muris was reported in two independent studies [48,72]. It was suggested that the contrasting findings might be the result of the use of distinct methods for the isolation and MS analysis of EVs [60].

Although most EV proteins identified in parasitic nematodes had been reported in previous ES proteomics studies, including vaccine candidates-such as SCP/TAPS proteins and metallopeptidases-EVs proteins in different nematode species tend to display diverse profiles. An analysis of EVs in proteomic datasets of parasitic nematodes showed that, except for a few eukaryotic EVs markers (e.g., heat shock proteins and 14-3-3 protein), only five EVs proteins were commonly observed in most of the nematode species studied: two M13 metallopeptidases, one actin, one transthyretin-like family proteins and one aspartic protease [60]. As mentioned, there is still a lack of understanding of the protein composition and amounts in nematode EVs. More in-depth proteomics and investigations are needed to gain valuable insights into nematode-specific EVs proteins.

\subsection{The Somatic Proteome}

Recently, significant progress has been made in the identification of somatic biomarkers or therapeutic targets in nematodes, employing proteomics and immunoproteomic approaches. Nevertheless, most investigations have focused on studying one or two developmental stages [54,73-78], and global investigations of developmental proteomes have only recently been tackled using high-throughput methods. Since the first systematic investigation of the somatic proteome of free-living and parasite stages of the human filarioid nematode, Brugia malayi, approximately a decade ago [23], there have been only two studies of other filarioids-Onchocerca volvulus and Onchocerca ochengi $[79,80]$, one of T. spiralis (trichina) [81] and another of Haemonchus contortus [22].

For Onchocerca ochengi, which is a model for Onchocerca volvulus (causing river blindness in people), Armstrong et al. [77] comprehensively characterised a total of 4260 unique proteins from multiple developmental stages (i.e., infective larvae, intrauterine microfilariae and adult worms) and fluid from intradermal nodules. Enzymes involved in redox and/or detoxification functions were widely distributed in all of the stages/samples studied, indicating that the parasite likely scavenges host-reactive oxygen and nitrogen species. The results also revealed an abundance of mitochondrial-related proteins in both vector-derived infective (L3) larvae and intrauterine microfilariae, highlighting that early larval stages of this species rely heavily on mitochondrial function for aerobic respiration. On the other hand, for Onchocerca volvulus, Bennuru et al. [80] reported a somatic proteome representing larval stages (i.e., L1, L2 and infective L3) derived from the black fly vector Simulium damnosum and ensuing larval and adult stages from the human host, which contained 7000 proteins. Overall, the global developmental proteome of Onchocerca volvulus was relatively consistent, in terms of protein composition, with that of the congener Onchocerca ochengi, but more distinct from that of the related species Brugia malayi [80].

In addition to these studies of filarioid nematodes, somatic proteomes have also been characterised for three different life stages ('newborn' larvae, 'muscle' larvae and adults) of Trichinella spiralis [81], and identified proteins expressed in a stage-specific manner. Overall, 1067 of 4691 (>20\%) proteins of Trichinella spiralis identified were differentially expressed among the three developmental stages studied. Many of these proteins appear to be regulated to meet the physiological and biochemical requirements of Trichinella spiralis at particular stages of development. For instance, significantly higher levels of antioxidantrelated molecules (e.g., thioredoxin peroxidases, peroxiredoxins and glutathione peroxidases) were identified in the adult stage of Trichinella spiralis compared with both newborn larvae and muscle larvae, indicating marked oxidative stress in this stage within the gut environment [81]. 
During the life-cycle of most parasitic nematodes, the initial larval stages grow substantially as they develop to the adult stage in a relatively short time period. In the case of Haemonchus contortus, it only takes about one month for the infective larvae ( 0.5 mm long) to grow into adult worms of $\sim 1.5-3.0 \mathrm{~cm}$ in length [82]. Thus, at molecular level, a strictly regulated nutritional metabolism pattern is expected, so that the high growth, cellular differentiation and developmental needs are met in the transition from the free-living to the parasitic phase of the life cycle. To gain molecular insight into the developmental biology of Haemonchus contortus, a total of 2487 proteins were identified and semi-quantified for five different developmental stages or sexes (i.e., eggs, L3s, L4s, and female and male adults) [22]. Bioinformatic analysis inferred that proteins involved in the metabolism of carbohydrates, amino acids and lipids or fatty acids were significantly upregulated, reflecting an increased demand for energy during the fast growth phase from the free-living to parasitic stages, similar to a previous transcriptional analysis of Haemonchus contortus $[83,84]$, indicating that nutritional metabolism is under tight post-transcriptional control.

\section{Conclusions and Opportunities for Future Research}

Proteomic studies of ES, EV and somatic proteins of parasitic nematodes can underpin molecular investigations of host-parasite interactions to enable the identification of intervention targets and diagnostic markers or biomarkers. However, there is still a long way to go to achieve a comprehensive appreciation of the complexities involved in these interactions and to apply this fundamental knowledge to achieve applied outcomes, such as the development of new interventions to combat nematode infections or nematodiases. A complementary multi-omics approach [13] is likely required to achieve a paradigm shift. Here, we discuss some possibilities for future research using high-throughput proteomic methods.

First, it will be important to study the dynamic changes in protein profiles in single cells of parasitic nematodes. Fortunately, both antibody-based and isobaric carrier-based single-cell proteomic approaches have been successfully applied to mammalian cells $[85,86]$, and we expect these methods to be applicable to invertebrate cells very soon. Although considerable work still needs to be done to optimize methods for the isolation and extraction of intact single cells from different nematode tissues, the prospects for proteomic analyses of single cells should allow profound insight into, and understanding of, nematode biology, which will better inform us about the mechanisms and pathways involved in host-nematode interactions.

Secondly, although most previous proteomics studies were focused on characterising ES and EV proteins, the molecules on the cuticle of worms cannot be ignored. Nematodes moult multiple times in their life cycle, replacing their existing cuticle with a fresh one each time. Consequently, a particular nematode species might display or express different proteins on the cuticular surface at different stages, as part of their immune evasion arsenal. For example, the attachment of host antibodies and leukocytes to the cuticle of Toxocara larvae stimulates rapid shedding of the surface coat, leaving behind an abandoned glycocalyx to which host immune cells remain attached [87]. Although surface proteintargeted proteomics has been conducted, to some extent, for nematode species such as Ascaris suum [88] and Strongyloides stercoralis [89], proteomic characterisation of cuticle surface-associated proteins in nematode has not drawn much attention. With the rapid development of MS imaging and the associated laser-capture microdissection approaches, the characterisation of tissue proteins in a high-throughput and spatial manner has become possible [90]. Future work should focus on utilising these modern approaches to unravel the composition and to quantify surface proteins exposed on the cuticle of nematodes, which could potentially disclose numerous biomarkers and therapeutic targets.

Another area worthy of pursuit is the study of post-translational modifications in parasitic nematodes using proteomics (mainly phosphoproteome and glycoproteome). Typically, these modification events often reversibly regulate the biochemical and physiological functions of associated proteins (e.g., phosphorylation versus dephosphorylation, and gly- 
cosylation versus deglycosylation), and also govern, to some extent, the cellular localisation of proteins [91]. Although there is currently scant knowledge of protein phosphorylation and glycosylation in parasitic nematodes, this is an emerging field in parasitology. To elucidate the roles of post-translational modifications in the host-nematode interaction, first, the occurrence of the various modification events in distinct developmental stages of nematodes should be explored in detail on a proteome-wide scale. Recently, two studies explored the phosphoproteome and N-glycoproteome of Haemonchus contortus, and shed the first light on some post-translational modifications in this parasitic nematode [92,93]. We hope that these advances in phosphoproteomics and glycoproteomics will stimulate similar investigations of other nematode species and will complement multiomic data sets to better understand the molecular aspects of host-nematode interactions.

Author Contributions: Conceptualisation, both authors; writing-original draft preparation, both authors; writing - review and editing, both authors; supervision, R.B.G.; funding acquisition, R.B.G. Both authors have read and agreed to the published version of the manuscript.

Funding: RBG's research program is supported by the Australian Research Council (ARC), the National Health and Medical Research Council (NHMRC) of Australia, and industry partners including Yourgene Health (Singapore) Pte Ltd.

Institutional Review Board Statement: https://research.unimelb.edu.au/work-with-us/ethicsand-integrity.

Informed Consent Statement: Not applicable.

Data Availability Statement: Not applicable.

Conflicts of Interest: The authors declare no conflict of interest.

\section{References}

1. Hotez, P.J.; Bundy, D.A.P.; Beegle, K.; Brooker, S.; Drake, L.; De Silva, N.; Montresor, A.; Engels, D.; Jukes, M.; Chitsulo, L.; et al. Helminth infections: Soil-transmitted helminth infections and schistosomiasis. In Disease Control Priorities in Developing Countries, 2nd ed.; Jamison, D.T., Breman, J.G., Measham, A.R., Alleyne, G., Claeson, M., Evans, D.B., Jha, P., Mills, A., Musgrove, P., Eds.; The World Bank and Oxford University Press: Washington, DC, USA, 2006.

2. Bartsch, S.M.; Hotez, P.J.; Asti, L.; Zapf, K.M.; Bottazzi, M.E.; Diemert, D.J.; Lee, B.Y. The global economic and health burden of human hookworm infection. PLoS Negl. Trop. Dis. 2016, 10, e004922. [CrossRef]

3. Charlier, J.; Van der Voort, M.; Kenyon, F.; Skuce, P.; Vercruysse, J. Chasing helminths and their economic impact on farmed ruminants. Trends Parasitol. 2014, 30, 361-367. [CrossRef]

4. Kaplan, R.M.; Vidyashankar, A.N. An inconvenient truth: Global worming and anthelmintic resistance. Vet. Parasitol. 2012, 186, 70-78. [CrossRef] [PubMed]

5. Martin, R.J.; Wolstenholme, A.J.; Caffrey, C.R. Anthelmintics: From discovery to resistance II (San Diego, 2016). Int. J. Parasitol. Drugs Drug Resist. 2016, 6, 297-298. [CrossRef] [PubMed]

6. Nisbet, A.J.; Meeusen, E.N.; Gonzalez, J.F.; Piedrafita, D.M. Immunity to Haemonchus contortus and vaccine development. Adv. Parasitol. 2016, 93, 353-396. [CrossRef]

7. Cooper, D.; Eleftherianos, I. Parasitic nematode immunomodulatory strategies: Recent advances and perspectives. Pathogens 2016, 5, 58. [CrossRef] [PubMed]

8. Geldhof, P.; De Maere, V.; Vercruysse, J.; Claerebout, E. Recombinant expression systems: The obstacle to helminth vaccines? Trends Parasitol. 2007, 23, 527-532. [CrossRef]

9. Jex, A.R.; Gasser, R.B.; Schwarz, E.M. Transcriptomic resources for parasitic nematodes of veterinary importance. Trends Parasitol. 2019, 35, 72-84. [CrossRef]

10. International Helminth Genomes Consortium. Comparative genomics of the major parasitic worms. Nat. Genet. 2019, 51, 163-174. [CrossRef] [PubMed]

11. Heck, M.; Neely, B.A. Proteomics in non-model organisms: A new analytical frontier. J. Proteome Res. 2020, 19, 3595-3606. [CrossRef]

12. Sotillo, J.; Toledo, R.; Mulvenna, J.; Loukas, A. Exploiting helminth-host interactomes through big data. Trends Parasitol. 2017, 33, 875-888. [CrossRef]

13. Ma, G.; Wang, T.; Korhonen, P.K.; Hofmann, A.; Sternberg, P.W.; Young, N.D.; Gasser, R.B. Elucidating the molecular and developmental biology of parasitic nematodes: Moving to a multiomics paradigm. Adv. Parasitol. 2020, 108, 175-229. [CrossRef]

14. Ma, G.; Gasser, R.B.; Wang, T.; Korhonen, P.K.; Young, N.D. Toward integrative 'omics of the barber's pole worm and related parasitic nematodes. Infect. Genet. Evol. 2020, 85, 104500. [CrossRef] [PubMed] 
15. Bennett, A.P.S.; Robinson, M.W. Trematode proteomics: Recent advances and future directions. Pathogens 2021, 10, 348. [CrossRef]

16. Van der Ree, A.M.; Mutapi, F. The helminth parasite proteome at the host-parasite interface-Informing diagnosis and control. Exp. Parasitol. 2015, 157, 48-58. [CrossRef] [PubMed]

17. Zhang, Y.; Fonslow, B.R.; Shan, B.; Baek, M.C.; Yates, J.R., III. Protein analysis by shotgun/bottom-up proteomics. Chem. Rev. 2013, 113, 2343-2394. [CrossRef] [PubMed]

18. Aebersold, R.; Mann, M. Mass-spectrometric exploration of proteome structure and function. Nature 2016, 537, 347-355. [CrossRef] [PubMed]

19. Lange, V.; Picotti, P.; Domon, B.; Aebersold, R. Selected reaction monitoring for quantitative proteomics: A tutorial. Mol. Syst. Biol. 2008, 4, 222. [CrossRef]

20. Yates, J.R., III. Mass spectrometry and the age of the proteome. J. Mass Spectrom. 1998, 33, 1-19. [CrossRef]

21. Maizels, R.M.; McSorley, H.J. Regulation of the host immune system by helminth parasites. J. Allergy Clin. Immunol. 2016, 138, 666-675. [CrossRef]

22. Wang, T.; Ma, G.; Ang, C.; Korhonen, P.K.; Rong, X.; Nie, S.; Koehler, A.V.; Simpson, R.J.; Greening, D.W.; Reid, G.E.; et al. Somatic proteome of Haemonchus contortus. Int. J. Parasitol. 2019, 49, 311-320. [CrossRef]

23. Bennuru, S.; Meng, Z.; Ribeiro, J.M.; Semnani, R.T.; Ghedin, E.; Chan, K.; Lucas, D.A.; Veenstra, T.D.; Nutman, T.B. Stage-specific proteomic expression patterns of the human filarial parasite Brugia malayi and its endosymbiont Wolbachia. Proc. Natl. Acad. Sci. USA 2011, 108, 9649-9654. [CrossRef]

24. Coakley, G.; Maizels, R.M.; Buck, A.H. Exosomes and other extracellular vesicles: The new communicators in parasite infections. Trends Parasitol. 2015, 31, 477-489. [CrossRef]

25. Cuesta-Astroz, Y.; Oliveira, F.S.; Nahum, L.A.; Oliveira, G. Helminth secretomes reflect different lifestyles and parasitized hosts. Int. J. Parasitol. 2017, 47, 529-544. [CrossRef]

26. Hewitson, J.P.; Harcus, Y.M.; Curwen, R.S.; Dowle, A.A.; Atmadja, A.K.; Ashton, P.D.; Wilson, A.; Maizels, R.M. The secretome of the filarial parasite, Brugia malayi: Proteomic profile of adult excretory-secretory products. Mol. Biochem. Parasitol. 2008, $160,8-21$. [CrossRef] [PubMed]

27. Hewitson, J.P.; Grainger, J.R.; Maizels, R.M. Helminth immunoregulation: The role of parasite secreted proteins in modulating host immunity. Mol. Biochem. Parasitol. 2009, 167, 1-11. [CrossRef]

28. Jourdan, P.M.; Lamberton, P.H.L.; Fenwick, A.; Addiss, D.G. Soil-transmitted helminth infections. Lancet 2017. [CrossRef]

29. Moyle, M.; Foster, D.L.; McGrath, D.E.; Brown, S.M.; Laroche, Y.; De Meutter, J.; Stanssens, P.; Bogowitz, C.A.; Fried, V.A.; Ely, J.A.; et al. A hookworm glycoprotein that inhibits neutrophil function is a ligand of the integrin CD11b/CD18. J. Biol. Chem. 1994, 269, 10008-10015. [CrossRef]

30. Abuzeid, A.M.I.; Zhou, X.; Huang, Y.; Li, G. Twenty-five-year research progress in hookworm excretory/secretory products. Parasites Vectors 2020, 13, 136. [CrossRef]

31. Morante, T.; Shepherd, C.; Constantinoiu, C.; Loukas, A.; Sotillo, J. Revisiting the Ancylostoma caninum secretome provides new information on hookworm-host interactions. Proteomics 2017, 17, 17. [CrossRef] [PubMed]

32. Mulvenna, J.; Hamilton, B.; Nagaraj, S.H.; Smyth, D.; Loukas, A.; Gorman, J.J. Proteomics analysis of the excretory/secretory component of the blood-feeding stage of the hookworm, Ancylostoma caninum. Mol. Cell. Proteomics 2009, 8, 109-121. [CrossRef]

33. Montano, K.J.; Cuellar, C.; Sotillo, J. Rodent models for the study of soil-transmitted helminths: A proteomics approach. Front. Cell Infect. Microbiol. 2021, 11, 639573. [CrossRef] [PubMed]

34. Logan, J.; Pearson, M.S.; Manda, S.S.; Choi, Y.J.; Field, M.; Eichenberger, R.M.; Mulvenna, J.; Nagaraj, S.H.; Fujiwara, R.T.; Gazzinelli-Guimaraes, P.; et al. Comprehensive analysis of the secreted proteome of adult Necator americanus hookworms. PLoS Negl Trop. Dis. 2020, 14, e0008237. [CrossRef] [PubMed]

35. Hewitson, J.P.; Harcus, Y.; Murray, J.; Van Agtmaal, M.; Filbey, K.J.; Grainger, J.R.; Bridgett, S.; Blaxter, M.L.; Ashton, P.D.; Ashford, D.A.; et al. Proteomic analysis of secretory products from the model gastrointestinal nematode Heligmosomoides polygyrus reveals dominance of venom allergen-like (VAL) proteins. J. Proteom. 2011, 74, 1573-1594. [CrossRef] [PubMed]

36. Sotillo, J.; Sanchez-Flores, A.; Cantacessi, C.; Harcus, Y.; Pickering, D.; Bouchery, T.; Camberis, M.; Tang, S.C.; Giacomin, P.; Mulvenna, J.; et al. Secreted proteomes of different developmental stages of the gastrointestinal nematode Nippostrongylus brasiliensis. Mol. Cell Proteom. 2014, 13, 2736-2751. [CrossRef]

37. Cantacessi, C.; Campbell, B.E.; Visser, A.; Geldhof, P.; Nolan, M.J.; Nisbet, A.J.; Matthews, J.B.; Loukas, A.; Hofmann, A.; Otranto, D.; et al. A portrait of the "SCP/TAPS" proteins of eukaryotes-developing a framework for fundamental research and biotechnological outcomes. Biotechnol. Adv. 2009, 27, 376-388. [CrossRef]

38. Wilbers, R.H.P.; Schneiter, R.; Holterman, M.H.M.; Drurey, C.; Smant, G.; Asojo, O.A.; Maizels, R.M.; Lozano-Torres, J.L. Secreted venom allergen-like proteins of helminths: Conserved modulators of host responses in animals and plants. PLoS Pathog. 2018, 14, e1007300. [CrossRef]

39. Maruszewska-Cheruiyot, M.; Szewczak, L.; Krawczak-Wojcik, K.; Glaczynska, M.; Donskow-Lysoniewska, K. The production of excretory-secretory molecules from Heligmosomoides polygyrus bakeri fourth stage larvae varies between mixed and single sex cultures. Parasit. Vectors 2021, 14, 106. [CrossRef]

40. Doyle, S.R.; Laing, R.; Bartley, D.J.; Britton, C.; Chaudhry, U.; Gilleard, J.S.; Holroyd, N.; Mable, B.K.; Maitland, K.; Morrison, A.A.; et al. A genome resequencing-based genetic map reveals the recombination landscape of an outbred parasitic nematode in the presence of polyploidy and polyandry. Genome Biol. Evol. 2018, 10, 396-409. [CrossRef] 
41. Wang, T.; Ma, G.; Ang, C.S.; Korhonen, P.K.; Koehler, A.V.; Young, N.D.; Nie, S.; Williamson, N.A.; Gasser, R.B. High throughput LC-MS/MS-based proteomic analysis of excretory-secretory products from short-term in vitro culture of Haemonchus contortus. J. Proteom. 2019, 204, 103375. [CrossRef]

42. Wang, T.; Van Steendam, K.; Dhaenens, M.; Vlaminck, J.; Deforce, D.; Jex, A.R.; Gasser, R.B.; Geldhof, P. Proteomic analysis of the excretory-secretory products from larval stages of Ascaris suum reveals high abundance of glycosyl hydrolases. PLoS Negl. Trop. Dis. 2013, 7, e2467. [CrossRef]

43. Gadahi, J.A.; Wang, S.; Bo, G.; Ehsan, M.; Yan, R.; Song, X.; Xu, L.; Li, X. Proteomic analysis of the excretory and secretory proteins of Haemonchus contortus (HcESP) binding to goat PBMCs in vivo revealed stage-specific binding profiles. PLoS ONE 2016, 11, e0159796. [CrossRef]

44. Lu, M.; Tian, X.; Zhang, Y.; Wang, W.; Tian, A.L.; Aimulajiang, K.; Liu, L.; Li, C.; Yan, R.; Xu, L.; et al. Protection studies of an excretory-secretory protein HcABHD against Haemonchus contortus infection. Vet. Res. 2021, 52, 3. [CrossRef] [PubMed]

45. Lu, M.; Tian, X.; Yang, Z.; Wang, W.; Tian, A.L.; Li, C.; Yan, R.; Xu, L.; Song, X.; Li, X. Proteomic analysis revealed T cell hyporesponsiveness induced by Haemonchus contortus excretory and secretory proteins. Vet. Res. 2020, 51, 65. [CrossRef] [PubMed]

46. Price, D.R.G.; Nisbet, A.J.; Frew, D.; Bartley, Y.; Oliver, E.M.; McLean, K.; Inglis, N.F.; Watson, E.; Corripio-Miyar, Y.; McNeilly, T.N. Characterisation of a niche-specific excretory-secretory peroxiredoxin from the parasitic nematode Teladorsagia circumcincta. Parasit. Vectors 2019, 12, 339. [CrossRef] [PubMed]

47. Chen, K.Y.; Lu, P.J.; Cheng, C.J.; Jhan, K.Y.; Yeh, S.C.; Wang, L.C. Proteomic analysis of excretory-secretory products from young adults of Angiostrongylus cantonensis. Mem. Inst. Oswaldo Cruz 2019, 114, e180556. [CrossRef]

48. Eichenberger, R.M.; Talukder, M.H.; Field, M.A.; Wangchuk, P.; Giacomin, P.; Loukas, A.; Sotillo, J. Characterization of Trichuris muris secreted proteins and extracellular vesicles provides new insights into host-parasite communication. J. Extracell. Vesicles 2018, 7, 1428004. [CrossRef]

49. Williams, S.E.; Brown, T.I.; Roghanian, A.; Sallenave, J.M. SLPI and elafin: One glove, many fingers. Clin. Sci. 2006, 110, 21-35. [CrossRef] [PubMed]

50. Leroux, L.P.; Nasr, M.; Valanparambil, R.; Tam, M.; Rosa, B.A.; Siciliani, E.; Hill, D.E.; Zarlenga, D.S.; Jaramillo, M.; Weinstock, J.V.; et al. Analysis of the Trichuris suis excretory/secretory proteins as a function of life cycle stage and their immunomodulatory properties. Sci. Rep. 2018, 8, 15921. [CrossRef]

51. Wang, Y.; Bai, X.; Tang, B.; Zhang, Y.; Zhang, L.; Cai, X.; Lin, J.; Jia, W.; Boireau, P.; Liu, M.; et al. Comparative analysis of excretory-secretory products of muscle larvae of three isolates of Trichinella pseudospiralis by the iTRAQ method. Vet. Parasitol. 2020, 109119. [CrossRef] [PubMed]

52. Wang, Y.; Bai, X.; Zhu, H.; Wang, X.; Shi, H.; Tang, B.; Boireau, P.; Cai, X.; Luo, X.; Liu, M.; et al. Immunoproteomic analysis of the excretory-secretory products of Trichinella pseudospiralis adult worms and newborn larvae. Parasit. Vectors 2017, 10, 579. [CrossRef] [PubMed]

53. Grzelak, S.; Stachyra, A.; Stefaniak, J.; Mrowka, K.; Moskwa, B.; Bien-Kalinowska, J. Immunoproteomic analysis of Trichinella spiralis and Trichinella britovi excretory-secretory muscle larvae proteins recognized by sera from humans infected with Trichinella. PLoS ONE 2020, 15, e0241918. [CrossRef]

54. Liu, R.D.; Qi, X.; Sun, G.G.; Jiang, P.; Zhang, X.; Wang, L.A.; Liu, X.L.; Wang, Z.Q.; Cui, J. Proteomic analysis of Trichinella spiralis adult worm excretory-secretory proteins recognized by early infection sera. Vet. Parasitol. 2016, 231, 43-46. [CrossRef]

55. Liu, R.D.; Jiang, P.; Wen, H.; Duan, J.Y.; Wang, L.A.; Li, J.F.; Liu, C.Y.; Sun, G.G.; Wang, Z.Q.; Cui, J. Screening and characterization of early diagnostic antigens in excretory-secretory proteins from Trichinella spiralis intestinal infective larvae by immunoproteomics. Parasitol. Res. 2016, 115, 615-622. [CrossRef]

56. Hasnain, S.Z.; McGuckin, M.A.; Grencis, R.K.; Thornton, D.J. Serine protease(s) secreted by the nematode Trichuris muris degrade the mucus barrier. PLoS Negl. Trop. Dis. 2012, 6, e1856. [CrossRef]

57. Xu, J.; Liu, R.D.; Bai, S.J.; Hao, H.N.; Yue, W.W.; Xu, Y.X.Y.; Long, S.R.; Cui, J.; Wang, Z.Q. Molecular characterization of a Trichinella spiralis aspartic protease and its facilitation role in larval invasion of host intestinal epithelial cells. PLoS Negl. Trop. Dis. 2020, 14, e0008269. [CrossRef] [PubMed]

58. Ren, H.N.; Zhuo, T.X.; Bai, S.J.; Bai, Y.; Sun, X.Y.; Dan Liu, R.; Long, S.R.; Cui, J.; Wang, Z.Q. Proteomic analysis of hydrolytic proteases in excretory/secretory proteins from Trichinella spiralis intestinal infective larvae using zymography combined with shotgun LC-MS/MS approach. Acta Trop. 2021, 216, 105825. [CrossRef] [PubMed]

59. Maeda, Y.; Palomares-Rius, J.E.; Hino, A.; Afrin, T.; Mondal, S.I.; Nakatake, A.; Maruyama, H.; Kikuchi, T. Secretome analysis of Strongyloides venezuelensis parasitic stages reveals that soluble and insoluble proteins are involved in its parasitism. Parasit. Vectors 2019, 12, 21. [CrossRef] [PubMed]

60. Sotillo, J.; Robinson, M.W.; Kimber, M.J.; Cucher, M.; Ancarola, M.E.; Nejsum, P.; Marcilla, A.; Eichenberger, R.M.; Tritten, L. The protein and microRNA cargo of extracellular vesicles from parasitic helminths-Current status and research priorities. Int. J. Parasitol. 2020, 50, 635-645. [CrossRef] [PubMed]

61. Wu, Z.; Wang, L.; Li, J.; Wang, L.; Wu, Z.; Sun, X. Extracellular vesicle-mediated communication within host-parasite interactions. Front. Immunol. 2018, 9, 3066. [CrossRef] [PubMed] 
62. Hansen, E.P.; Fromm, B.; Andersen, S.D.; Marcilla, A.; Andersen, K.L.; Borup, A.; Williams, A.R.; Jex, A.R.; Gasser, R.B.; Young, N.D.; et al. Exploration of extracellular vesicles from Ascaris suum provides evidence of parasite-host cross talk. J. Extracell. Vesicles 2019, 8, 1578116. [CrossRef] [PubMed]

63. Zamanian, M.; Fraser, L.M.; Agbedanu, P.N.; Harischandra, H.; Moorhead, A.R.; Day, T.A.; Bartholomay, L.C.; Kimber, M.J. Release of small RNA-containing exosome-like vesicles from the human filarial parasite Brugia malayi. PLoS Negl. Trop. Dis. 2015, 9, e0004069. [CrossRef] [PubMed]

64. Harischandra, H.; Yuan, W.; Loghry, H.J.; Zamanian, M.; Kimber, M.J. Profiling extracellular vesicle release by the filarial nematode Brugia malayi reveals sex-specific differences in cargo and a sensitivity to ivermectin. PLoS Negl. Trop. Dis. 2018, 12, e0006438. [CrossRef] [PubMed]

65. Buck, A.H.; Coakley, G.; Simbari, F.; McSorley, H.J.; Quintana, J.F.; Le Bihan, T.; Kumar, S.; Abreu-Goodger, C.; Lear, M.; Harcus, Y.; et al. Exosomes secreted by nematode parasites transfer small RNAs to mammalian cells and modulate innate immunity. Nat. Commun. 2014, 5, 5488. [CrossRef]

66. Eichenberger, R.M.; Ryan, S.; Jones, L.; Buitrago, G.; Polster, R.; Montes de Oca, M.; Zuvelek, J.; Giacomin, P.R.; Dent, L.A.; Engwerda, C.R.; et al. Hookworm secreted extracellular vesicles interact with host cells and prevent inducible colitis in mice. Front. Immunol. 2018, 9, 850. [CrossRef]

67. Tzelos, T.; Matthews, J.B.; Buck, A.H.; Simbari, F.; Frew, D.; Inglis, N.F.; McLean, K.; Nisbet, A.J.; Whitelaw, C.B.; Knox, D.P.; et al. A preliminary proteomic characterisation of extracellular vesicles released by the ovine parasitic nematode, Teladorsagia circumcincta. Vet. Parasitol. 2016, 221, 84-92. [CrossRef]

68. Gao, X.; Yang, Y.; Liu, X.; Wang, Y.; Yang, Y.; Boireau, P.; Liu, M.; Bai, X. Extracellular vesicles derived from Trichinella spiralis prevent colitis by inhibiting M1 macrophage polarization. Acta Trop. 2021, 213, 105761. [CrossRef]

69. Boysen, A.T.; Whitehead, B.; Stensballe, A.; Carnerup, A.; Nylander, T.; Nejsum, P. Fluorescent labeling of helminth extracellular vesicles using an in vivo whole organism approach. Biomedicines 2020, 8, 213. [CrossRef] [PubMed]

70. Hansen, E.P.; Kringel, H.; Williams, A.R.; Nejsum, P. Secretion of RNA-containing extracellular vesicles by the porcine whipworm, Trichuris suis. J. Parasitol. 2015, 101, 336-340. [CrossRef] [PubMed]

71. Shears, R.K.; Bancroft, A.J.; Hughes, G.W.; Grencis, R.K.; Thornton, D.J. Extracellular vesicles induce protective immunity against Trichuris muris. Parasite Immunol. 2018, 40, e12536. [CrossRef]

72. Tritten, L.; Tam, M.; Vargas, M.; Jardim, A.; Stevenson, M.M.; Keiser, J.; Geary, T.G. Excretory/secretory products from the gastrointestinal nematode Trichuris muris. Exp. Parasitol. 2017, 178, 30-36. [CrossRef]

73. Stoltzfus, J.D.; Pilgrim, A.A.; Herbert, D.R. Perusal of parasitic nematode 'omics in the post-genomic era. Mol. Biochem. Parasitol. 2017, 215, 11-22. [CrossRef]

74. Yang, J.; Pan, W.; Sun, X.; Zhao, X.; Yuan, G.; Sun, Q.; Huang, J.; Zhu, X. Immunoproteomic profile of Trichinella spiralis adult worm proteins recognized by early infection sera. Parasit. Vectors 2015, 8, 20. [CrossRef] [PubMed]

75. Zawistowska-Deniziak, A.; Powazka, K.; Pekacz, M.; Basalaj, K.; Klockiewicz, M.; Wisniewski, M.; Mlocicki, D. Immunoproteomic analysis of Dirofilaria repens microfilariae and adult parasite stages. Pathogens 2021, 10, 174. [CrossRef]

76. Morchon, R.; Gonzalez-Miguel, J.; Carreton, E.; Kramer, L.H.; Valero, L.; Montoya-Alonso, J.A.; Simon, F.; Siles-Lucas, M. Proteomic analysis of the somatic and surface compartments from Dirofilaria immitis adult worms. Vet. Parasitol. 2014, 203, 144-152. [CrossRef]

77. Rodpai, R.; Intapan, P.M.; Thanchomnang, T.; Sanpool, O.; Janwan, P.; Laummaunwai, P.; Wongkham, C.; Insawang, T.; Maleewong, W. Identification of antigenic proteins in Strongyloides stercoralis by proteomic analysis. Parasitol. Res. 2017, 116, 1687-1693. [CrossRef] [PubMed]

78. Ren, H.N.; Liu, R.D.; Song, Y.Y.; Zhuo, T.X.; Guo, K.X.; Zhang, Y.; Jiang, P.; Wang, Z.Q.; Cui, J. Label-free quantitative proteomic analysis of molting-related proteins of Trichinella spiralis intestinal infective larvae. Vet. Res. 2019, 50, 70. [CrossRef]

79. Armstrong, S.D.; Xia, D.; Bah, G.S.; Krishna, R.; Ngangyung, H.F.; LaCourse, E.J.; McSorley, H.J.; Kengne-Ouafo, J.A.; ChounnaNdongmo, P.W.; Wanji, S.; et al. Stage-specific proteomes from Onchocerca ochengi, sister species of the human river blindness parasite, uncover adaptations to a nodular lifestyle. Mol. Cell. Proteom. 2016, 15, 2554-2575. [CrossRef]

80. Bennuru, S.; Cotton, J.A.; Ribeiro, J.M.; Grote, A.; Harsha, B.; Holroyd, N.; Mhashilkar, A.; Molina, D.M.; Randall, A.Z.; Shandling, A.D.; et al. Stage-specific transcriptome and proteome analyses of the filarial parasite Onchocerca volvulus and its Wolbachia endosymbiont. mBio 2016, 7. [CrossRef] [PubMed]

81. Liu, J.Y.; Zhang, N.Z.; Li, W.H.; Li, L.; Yan, H.B.; Qu, Z.G.; Li, T.T.; Cui, J.M.; Yang, Y.; Jia, W.Z.; et al. Proteomic analysis of differentially expressed proteins in the three developmental stages of Trichinella spiralis. Vet. Parasitol. 2016, 231, 32-38. [CrossRef]

82. Veglia, F. The Anatomy and Life-history of the Haemonchus contortus (Rud.). Rep. Dir. Vet. Res. S. Afr. 1915, 3, 347-500.

83. Schwarz, E.M.; Korhonen, P.K.; Campbell, B.E.; Young, N.D.; Jex, A.R.; Jabbar, A.; Hall, R.S.; Mondal, A.; Howe, A.C.; Pell, J.; et al. The genome and developmental transcriptome of the strongylid nematode Haemonchus contortus. Genome Biol. 2013, 14, R89. [CrossRef] [PubMed]

84. Ma, G.; Wang, T.; Korhonen, P.K.; Ang, C.S.; Williamson, N.A.; Young, N.D.; Stroehlein, A.J.; Hall, R.S.; Koehler, A.V.; Hofmann, A.; et al. Molecular alterations during larval development of Haemonchus contortus in vitro are under tight posttranscriptional control. Int. J. Parasitol. 2018, 48, 763-772. [CrossRef] [PubMed] 
85. Specht, H.; Emmott, E.; Petelski, A.A.; Huffman, R.G.; Perlman, D.H.; Serra, M.; Kharchenko, P.; Koller, A.; Slavov, N. Single-cell proteomic and transcriptomic analysis of macrophage heterogeneity using SCoPE2. Genome Biol. 2021, 22, 50. [CrossRef] [PubMed]

86. Slavov, N. Unpicking the proteome in single cells. Science 2020, 367, 512-513. [CrossRef] [PubMed]

87. Page, A.P.; Rudin, W.; Fluri, E.; Blaxter, M.L.; Maizels, R.M. Toxocara canis: A labile antigenic surface coat overlying the epicuticle of infective larvae. Exp. Parasitol. 1992, 75, 72-86. [CrossRef]

88. Wang, T. Transcriptomic and proteomic analysis of Ascaris suum larvae during their hepato-tracheal migration. Ph.D. Thesis, Ghent University, Ghent, Belgium, 2014.

89. Marcilla, A.; Sotillo, J.; Perez-Garcia, A.; Igual-Adell, R.; Valero, M.L.; Sanchez-Pino, M.M.; Bernal, D.; Munoz-Antoli, C.; Trelis, M.; Toledo, R.; et al. Proteomic analysis of Strongyloides stercoralis L3 larvae. Parasitology 2010, 137, 1577-1583. [CrossRef]

90. Ryan, D.J.; Spraggins, J.M.; Caprioli, R.M. Protein identification strategies in MALDI imaging mass spectrometry: A brief review. Curr. Opin. Chem. Biol. 2019, 48, 64-72. [CrossRef]

91. Mann, M.; Jensen, O.N. Proteomic analysis of post-translational modifications. Nat. Biotechnol. 2003, 21, 255-261. [CrossRef]

92. Wang, T.; Ma, G.; Ang, C.S.; Korhonen, P.K.; Stroehlein, A.J.; Young, N.D.; Hofmann, A.; Chang, B.C.H.; Williamson, N.A.; Gasser, R.B. The developmental phosphoproteome of Haemonchus contortus. J. Proteom. 2020, 213, 103615. [CrossRef]

93. Wang, C.; Gao, W.; Yan, S.; Zhu, X.Q.; Suo, X.; Liu, X.; Gupta, N.; Hu, M. N-glycome and N-glycoproteome of a hematophagous parasitic nematode Haemonchus. Comput. Struct. Biotechnol. J. 2021, 19, 2486-2496. [CrossRef] [PubMed] 